\title{
CONVERSÃO E BALANÇO ENERGÉTICO DE SISTEMAS DE SUCESSÃO E DE ROTAÇÃO DE CULTURAS
}

\author{
ENERGY CONVERSION AND BALANCE OF CROP SUCCESSION \\ AND ROTATION SYSTEMS
}

\author{
Henrique Pereira dos Santos ${ }^{1}$ Julio Cesar Barreneche Lhamby ${ }^{2}$ \\ João Carlos Ignaczak ${ }^{3}$ Guido André Schneider ${ }^{4}$
}

\section{RESUMO}

Do ponto de vista calórico, existem poucos trabalhos no Brasil estimando a conversão e o balanço energético. Neste estudo, avaliaram-se a conversão e o balanço energético de sete sistemas de rotação de culturas durante nove anos (1987 a 1995), em Passo Fundo, RS. Os sistemas foram constituídos por: sistema I (trigo/soja); sistema II (trigo/soja, de 1987 a 1989, e trigo/soja e ervilhaca/ milho ou sorgo, de 1990 a 1995); sistema III (trigo/soja, aveia preta ou aveia branca/soja e ervilhaca/milho ou sorgo); sistema IV (trigo/soja, aveia branca/soja, linho/soja e ervilhaca/milho, de 1987 a 1989, e trigo/soja, girassol ou aveia preta/soja, aveia branca/soja e ervilhaca/milho ou sorgo, de 1990 a 1995); sistema V (trigo/soja, trigo/soja, aveia preta ou aveia branca/soja e ervilhaca/milho ou sorgo); sistema VI (trigo/ soja, trigo/soja, aveia branca/soja, linho/soja e ervilhaca/milho, de 1987 a 1989, e trigo/soja, trigo/soja, girassol ou aveia preta/soja, aveia branca/soja e ervilhaca/milho ou sorgo, de 1990 a 1995); e VII (pousio de inverno/soja, de 1990 a 1995). No período agrícola de 1987 a 1989, não houve diferenças significativas entre os sistemas de rotação de culturas, em relação à conversão energética e ao balanço energético. Na média do período de 1990 a 1995, o sistema II $(8,58)$ apresentou índice de conversão energética maior do que o do sistema I (5,61), e os demais sistemas não diferiram significativamente entre si. No mesmo período, o balanço energético para os sistemas II (20.938Mcal/ha), III (19.239Mcal/ha), IV (18.618Mcal/ha), V (19.646kg/Mcal) e VI (18.702Mcal/ha) foi superior ao do sistema VII (10.279Mcal/ha). A rotação de culturas foi mais eficiente, sem aumentar o consumo de energia não renovável.

Palavras-chave:

energia, conversão energética, balanço energético, caloria, rendimento de grãos.

\section{SUMMARY}

Energy conversion and balance of seven crop rotation systems for wheat were assessed from 1987 to 1995, in Passo Fundo, RS, Brazil. The following systems were evaluated: system I (wheat/soybean); system II (wheat/soybean, from 1987 to 1989, and wheat/soybean and common vetch/corn or sorghum, from 1990 to 1995); system III (wheat/soybean, black oats or white oats/soybean, and common vetch/corn or sorghum); system IV (wheat/soybean, white oats/soybean, flax/soybean, and common vetch/corn, from 1987 to 1989, and wheat/soybean, sunflower or black oats/soybean, white oats/soybean, and common vetch/corn or sorghum, from 1990 to 1995); system V (wheat/soybean, wheat/soybean, black oats or white oats/soybean, and common vetch/corn or sorghum); system VI (wheat/soybean, wheat/soybean, white oats/soybean, flax/soybean, and common vetch/corn, from 1987 to 1989, and wheat/soybean, wheat/soybean, sunflower or black oats/soybean, white oats/soybean, and common vetch/corn or sorghum, from 1990 to 1995); and VII (winter fallow/soybean, from 1990 to 1995). On the average from1987 to 1989, no significant differences among rotation systems were observed for energy conversion and energy balance rates. From 1990 to 1995, system II (8.58) showed greater energy conversion index than system I (5.61), and the remaining systems did not differ significantly among themselves. From 1990 to 1995, systems II (20,938Mcal/ha), III (19,239Mcal/ha), IV (18,618Mcal/ha), V (19.646Mcal/ha), and VI (18,702Mcal/ha) showed greater energy balance, as compared to system VII (10.279kg/Mcal).

Key words: energy, energy conversion, energy balance, calorie, yield.

\footnotetext{
${ }^{1}$ Engenheiro Agrônomo, Doutor, Embrapa-Centro Nacional de Pesquisa de Trigo (CNPT), CP 451, 99001-970, Passo Fundo, RS. Autor para correspondência. Email: hpsantos@cnpt.embrapa.br. Bolsista CNPq.

${ }^{2}$ Engenheiro Agrônomo, Doutor, Embrapa-CNPT.

${ }^{3}$ Engenheiro Agrônomo, MSc., Embrapa-CNPT.

${ }^{4}$ Acadêmico de Agronomia da Universidade de Passo Fundo-FAMV. Bolsista CNPq.
} Recebido para publicação em 20.12.99. Aprovado em 05.07.00 


\section{INTRODUÇÃO}

A monocultura, ou mesmo o sistema de sucessão trigo/soja, continuamente, pode provocar a degradação física, química e biológica do solo e, conseqüentemente, a queda da produtividade das culturas (MUZILLI, 1985). Também proporciona condições mais favoráveis ao desenvolvimento de doenças, pragas e plantas daninhas (REIS \& SANTOS, 1993; ROMAN \& VELLOSO, 1993).

A rotação de culturas pode ser definida como uma prática agrícola em que diferentes culturas são implementadas seguindo uma ordem definida ou uma sequiência de culturas na área, em anos distintos (SANTOS et al., 1993). Assim, a rotação de culturas como prática corrente na produção agrícola tem recebido ao longo do tempo o reconhecimento, do ponto de vista técnico, como um dos meios indispensáveis ao desenvolvimento de uma agricultura estável, em termos de sustentabilidade..

Por outro lado, estudos demonstram que uma forma mais adequada para avaliar o nível de desenvolvimento da agricultura de uma região consiste na análise dos fluxos de energia associados a essa atividade (PIMENTEL, 1980b). A relação entre a energia acumulada nos alimentos produzidos e a energia fóssil acumulada nos insumos gastos para a produção (combustíveis, fertilizantes, fungicidas, herbicidas e inseticidas) constitui um instrumento para avaliar o grau de sustentabilidade da agricultura, ou seja, a energia obtida tem de ser maior do que a consumida.

Dentro dessa idéia, existem vários trabalhos desenvolvidos em diversos países, como por exemplo na Alemanha, Brasil, Canadá, Estados Unidos, França, Índia e Inglaterra, onde essa relação foi estudada em monocultivo (WHITE, 1975; BERARDI, 1978; PIMENTEL, 1980b; WILSON \& BRIGSTOCKE, 1980; QUESADA et al., 1987; BOHRA et al., 1990). Porém há poucas pesquisas relativas ao estudo da conversão energética e do balanço energético em sistemas de rotação de culturas.

No Canadá, estudos com 12 sistemas de rotação de culturas para trigo, durante 12 e 18 anos, respectivamente, apresentaram diferenças significativas na conversão energética, entre os sistemas estudados (ZENTNER et al., 1984, 1989). Nessa pesquisa, apenas uma cultura foi avaliada a cada ano.

$\mathrm{Na}$ avaliação de experimentos de sistemas rotação de culturas para trigo, em Passo Fundo, RS, e região durante dez anos, sob preparo convencional de solo, no inverno, e sob sistema plantio direto, no verão, não foram encontradas diferenças significati- vas entre os sistemas estudados para o índice de produtividade cultural (SANTOS et al.,1995). Em estudo desenvolvido para a região de Guarapuava, PR, durante dez anos sob sistema plantio direto, verificaram-se índices de produtividade cultural mais elevados para os sistemas de rotação de culturas, em relação à monocultura de trigo (SANTOS $\boldsymbol{e} t$ al., 1996b). Em sistemas mistos de rotação de culturas (lavoura + pecuária), durante seis anos sob sistema plantio direto, na região de Passo Fundo, RS, SANTOS et al. (1996a) observaram diferenças significativas para o índice de conversão energética e balanço energético dos sistemas.

$\mathrm{O}$ presente trabalho teve por objetivo avaliar a conversão e o balanço energético de sistemas de sucessão e de rotação de culturas.

\section{MATERIAL E MÉTODOS}

Nesta pesquisa foram empregados dados obtidos no experimento de sistemas de rotação de culturas para trigo instalado na Embrapa-Centro Nacional de Pesquisa de Trigo, em Passo Fundo, RS, no período de 1987 a 1995, em Latossolo Vermelho, distrófico típico. A área experimental vinha sendo cultivada anteriormente com trigo, no inverno, e com soja, no verão.

Os tratamentos consistiram em sete sistemas de rotação de culturas: sistema I (trigo/soja); sistema II (trigo/soja, de 1987 a 1989, e trigo/soja e ervilhaca/milho ou sorgo, de 1990 a 1995); sistema III (trigo/soja, aveia preta ou aveia branca/soja e ervilhaca/milho ou sorgo); sistema IV (trigo/soja, aveia branca/soja, linho/soja e ervilhaca/milho, de 1987 a 1989, e trigo/soja, girassol ou aveia preta/soja, aveia branca/soja e ervilhaca/milho ou sorgo, de 1990 a 1995); sistema V (trigo/soja, trigo/soja, aveia preta ou aveia branca/soja e ervilhaca/milho ou sorgo); sistema VI (trigo/soja, trigo/soja, aveia branca/soja, linho/soja e ervilhaca/milho, de 1987 a 1989, e trigo/soja, trigo/soja, girassol ou aveia preta/soja, aveia branca/soja e ervilhaca/milho ou sorgo, de 1990 a 1995); e sistema VII (pousio de inverno/soja), a partir de 1990 (Tabela 1). As culturas de inverno foram estabelecidas sob preparo convencional de solo, e as de verão, sob semeadura direta. Em 1990, foram adicionadas duas parcelas por repetição, para completar o sistema II e para pousio de inverno antecedendo a soja (sistema VII). A partir de 1990, no terceiro e no quinto sistema de rotação, a sucessão aveia preta/soja foi substituída por aveia branca/soja. Nesse mesmo ano (1990), no quarto e no sexto sistema de rotação, a sucessão linho/soja foi substituída por girassol. A partir de 1993, nesses mesmos sistemas, o girassol foi substituído pela 
Tabela 1 - Sistemas de rotação de culturas com espécies de inverno e de verão. Passo Fundo, RS.

\begin{tabular}{|c|c|c|c|c|c|c|c|c|c|}
\hline \multirow[t]{2}{*}{ Sistema de rotação } & \multicolumn{9}{|c|}{ Ano } \\
\hline & 1987 & 1988 & 1989 & 1990 & 1991 & 1992 & 1993 & 1994 & 1995 \\
\hline Sistema I & $\mathrm{T} / \mathrm{S}$ & $\mathrm{T} / \mathrm{S}$ & $\mathrm{T} / \mathrm{S}$ & $\mathrm{T} / \mathrm{S}$ & $\mathrm{T} / \mathrm{S}$ & $\mathrm{T} / \mathrm{S}$ & $\mathrm{T} / \mathrm{S}$ & $\mathrm{T} / \mathrm{S}$ & $\mathrm{T} / \mathrm{S}$ \\
\hline \multirow[t]{2}{*}{ Sistema II } & $\mathrm{T} / \mathrm{S}$ & $\mathrm{T} / \mathrm{S}$ & $\mathrm{T} / \mathrm{S}$ & $\mathrm{E} / \mathrm{M}$ & $\mathrm{T} / \mathrm{S}$ & $\mathrm{E} / \mathrm{M}$ & $\mathrm{T} / \mathrm{S}$ & E/So & $\mathrm{T} / \mathrm{S}$ \\
\hline & & & & $\mathrm{T} / \mathrm{S}$ & $\mathrm{E} / \mathrm{M}$ & $\mathrm{T} / \mathrm{S}$ & $\mathrm{E} / \mathrm{M}$ & $\mathrm{T} / \mathrm{S}$ & E/So \\
\hline \multirow[t]{3}{*}{ Sistema III } & $\mathrm{T} / \mathrm{S}$ & $\mathrm{Ap} / \mathrm{S}$ & $\mathrm{E} / \mathrm{M}$ & $\mathrm{T} / \mathrm{S}$ & $\mathrm{Ab} / \mathrm{S}$ & $\mathrm{E} / \mathrm{M}$ & $\mathrm{T} / \mathrm{S}$ & $\mathrm{Ab} / \mathrm{S}$ & E/So \\
\hline & $\mathrm{Ap} / \mathrm{S}$ & $\mathrm{E} / \mathrm{M}$ & $\mathrm{T} / \mathrm{S}$ & $\mathrm{Ab} / \mathrm{S}$ & $\mathrm{E} / \mathrm{M}$ & $\mathrm{T} / \mathrm{S}$ & $\mathrm{Ab} / \mathrm{S}$ & E/So & $\mathrm{T} / \mathrm{S}$ \\
\hline & $\mathrm{E} / \mathrm{M}$ & $\mathrm{T} / \mathrm{S}$ & $\mathrm{Ap} / \mathrm{S}$ & $\mathrm{E} / \mathrm{M}$ & $\mathrm{T} / \mathrm{S}$ & $\mathrm{Ab} / \mathrm{S}$ & $\mathrm{E} / \mathrm{M}$ & $\mathrm{T} / \mathrm{S}$ & $\mathrm{Ab} / \mathrm{S}$ \\
\hline \multirow[t]{4}{*}{ Sistema IV } & $\mathrm{T} / \mathrm{S}$ & $\mathrm{Ab} / \mathrm{S}$ & $\mathrm{L} / \mathrm{S}$ & $\mathrm{E} / \mathrm{M}$ & $\mathrm{T} / \mathrm{S}$ & Gir & $\mathrm{Ab} / \mathrm{S}$ & E/So & $\mathrm{T} / \mathrm{S}$ \\
\hline & $\mathrm{Ab} / \mathrm{S}$ & $\mathrm{L} / \mathrm{S}$ & $\mathrm{E} / \mathrm{M}$ & $\mathrm{T} / \mathrm{S}$ & Gir & $\mathrm{Ab} / \mathrm{S}$ & $\mathrm{E} / \mathrm{M}$ & $\mathrm{T} / \mathrm{S}$ & $\mathrm{Ap} / \mathrm{S}$ \\
\hline & $\mathrm{L} / \mathrm{S}$ & $\mathrm{E} / \mathrm{M}$ & $\mathrm{T} / \mathrm{S}$ & Gir & $\mathrm{Ab} / \mathrm{S}$ & $\mathrm{E} / \mathrm{M}$ & $\mathrm{T} / \mathrm{S}$ & Ap/S & $\mathrm{Ab} / \mathrm{s}$ \\
\hline & $\mathrm{E} / \mathrm{M}$ & $\mathrm{T} / \mathrm{S}$ & $\mathrm{Ab} / \mathrm{S}$ & $\mathrm{Ab} / \mathrm{S}$ & $\mathrm{E} / \mathrm{M}$ & $\mathrm{T} / \mathrm{S}$ & $\mathrm{Ap} / \mathrm{S}$ & $\mathrm{Ab} / \mathrm{S}$ & E/So \\
\hline \multirow[t]{4}{*}{ Sistema V } & $\mathrm{T} / \mathrm{S}$ & $\mathrm{T} / \mathrm{S}$ & $\mathrm{Ap} / \mathrm{S}$ & $\mathrm{E} / \mathrm{M}$ & $\mathrm{T} / \mathrm{S}$ & $\mathrm{T} / \mathrm{S}$ & $\mathrm{Ab} / \mathrm{S}$ & E/So & $\mathrm{T} / \mathrm{S}$ \\
\hline & $\mathrm{T} / \mathrm{S}$ & $\mathrm{Ap} / \mathrm{S}$ & $\mathrm{E} / \mathrm{M}$ & $\mathrm{T} / \mathrm{S}$ & $\mathrm{T} / \mathrm{S}$ & $\mathrm{Ab} / \mathrm{S}$ & $\mathrm{E} / \mathrm{M}$ & $\mathrm{T} / \mathrm{S}$ & $\mathrm{T} / \mathrm{S}$ \\
\hline & $\mathrm{Ap} / \mathrm{S}$ & $\mathrm{E} / \mathrm{M}$ & $\mathrm{T} / \mathrm{S}$ & $\mathrm{T} / \mathrm{S}$ & $\mathrm{Ab} / \mathrm{S}$ & $\mathrm{E} / \mathrm{M}$ & $\mathrm{T} / \mathrm{S}$ & $\mathrm{T} / \mathrm{S}$ & $\mathrm{Ab} / \mathrm{S}$ \\
\hline & $\mathrm{E} / \mathrm{M}$ & $\mathrm{T} / \mathrm{S}$ & $\mathrm{T} / \mathrm{S}$ & $\mathrm{Ab} / \mathrm{S}$ & $\mathrm{E} / \mathrm{M}$ & $\mathrm{T} / \mathrm{S}$ & $\mathrm{T} / \mathrm{S}$ & $\mathrm{Ab} / \mathrm{S}$ & E/So \\
\hline \multirow[t]{5}{*}{ Sistema VI } & $\mathrm{T} / \mathrm{S}$ & $\mathrm{T} / \mathrm{S}$ & $\mathrm{Ab} / \mathrm{S}$ & $\mathrm{Ab} / \mathrm{S}$ & $\mathrm{E} / \mathrm{M}$ & $\mathrm{T} / \mathrm{S}$ & $\mathrm{T} / \mathrm{S}$ & $\mathrm{Ap} / \mathrm{S}$ & $\mathrm{Ab} / \mathrm{S}$ \\
\hline & $\mathrm{T} / \mathrm{S}$ & $\mathrm{Ab} / \mathrm{S}$ & $\mathrm{L} / \mathrm{S}$ & $\mathrm{E} / \mathrm{M}$ & $\mathrm{T} / \mathrm{S}$ & $\mathrm{T} / \mathrm{S}$ & $\mathrm{Ap} / \mathrm{S}$ & $\mathrm{Ab} / \mathrm{S}$ & E/So \\
\hline & $\mathrm{Ab} / \mathrm{S}$ & $\mathrm{L} / \mathrm{S}$ & $\mathrm{E} / \mathrm{M}$ & $\mathrm{T} / \mathrm{S}$ & $\mathrm{T} / \mathrm{S}$ & Gir & $\mathrm{Ab} / \mathrm{S}$ & E/So & $\mathrm{T} / \mathrm{S}$ \\
\hline & $\mathrm{L} / \mathrm{S}$ & $\mathrm{E} / \mathrm{M}$ & $\mathrm{T} / \mathrm{S}$ & $\mathrm{T} / \mathrm{S}$ & Gir & $\mathrm{Ab} / \mathrm{S}$ & $\mathrm{E} / \mathrm{M}$ & $\mathrm{T} / \mathrm{S}$ & $\mathrm{T} / \mathrm{S}$ \\
\hline & $\mathrm{E} / \mathrm{M}$ & $\mathrm{T} / \mathrm{S}$ & $\mathrm{T} / \mathrm{S}$ & Gir & $\mathrm{Ab} / \mathrm{S}$ & $\mathrm{E} / \mathrm{M}$ & $\mathrm{T} / \mathrm{S}$ & $\mathrm{T} / \mathrm{S}$ & $\mathrm{Ap} / \mathrm{S}$ \\
\hline Sistema VII & & & & $\mathrm{P} / \mathrm{S}$ & $\mathrm{P} / \mathrm{S}$ & $\mathrm{P} / \mathrm{S}$ & $\mathrm{P} / \mathrm{S}$ & $\mathrm{P} / \mathrm{S}$ & $\mathrm{P} / \mathrm{S}$ \\
\hline
\end{tabular}

$\mathrm{Ab}=$ aveia branca; $\mathrm{Ap}=$ aveia preta $\mathrm{E}=$ ervilhaca $; \mathrm{Gir}=$ girassol $; \mathrm{L}=$ linho; $\mathrm{M}=$ milho, $\mathrm{P}=$ pousio $; \mathrm{S}=$ soja; $\mathrm{So}=\mathrm{Sorgo} ; \mathrm{e} \mathrm{T}=$ trigo.

sucessão aveia preta/soja. Em 1994, o milho foi substituído por sorgo.

A adubação de manutenção foi realizada de acordo com a recomendação para cada cultura e baseada nos resultados da análise de solo (COMISSÃO, 1995). As amostras de solo foram coletadas sempre após a colheita das culturas de inverno e de verão.

A semeadura, o controle de plantas daninhas e os tratamentos fitossanitários foram realizados de acordo com a recomendação das comissões de pesquisa específicas para cada cultura, e a colheita foi realizada com colhedora especial para parcelas. O rendimento de grãos de aveia branca, de girassol, de milho, de soja e de trigo foi corrigido para umidade de $13 \%$ e o de linho, para $10 \%$.

A conversão energética dos sistemas estudados foi calculada pela razão entre a energia produzida pela consumida, em cada sistema. O balanço energético dos sistemas estudados foi calculado mediante a diferença entre a energia produzida e a consumida, em cada sistema. Como energia produzida considerou-se a estimativa da transformação do rendimento de grãos (aveia branca, girassol, linho, milho, soja, trigo e sorgo), da matéria seca (aveia preta) ou da quantidade de $\mathrm{N}$ na matéria seca (ervilhaca) em energia. Como energia consumida considerou-se a soma dos coeficientes energéticos equivalentes aos corretivos, aos fertilizantes, às sementes, aos fungicidas, aos herbicidas e aos inseticidas, usados em cada sistema, bem como a energia consumida pelas operações de semeadura, de adubação, de aplicação de produtos, de adubação nitrogenada e de colheita.

No presente estudo, para o cálculo de diversos índices envolvendo sistemas, rendimento de grãos, matéria seca, quantidade de $\mathrm{N}$ na matéria seca e operações de campo, foram empregados dados e orientações gerados por HEICHEL (1980), por PIMENTEL (1980a; 1980b), por MARCHIORO (1985), por MELLO (1986), por ZENTNER et al. (1989), por EMBRAPA (1991) e por FREITAS et al. (1994). No caso de aveia preta e de ervilhaca, de 1989 a 1993, foi considerada como rendimento a contribuição ao solo de $90 \mathrm{~kg} \mathrm{ha}^{-1}$ de N (DERPSCH \& CALEGARI, 1992).

O delineamento experimental foi de blocos ao acaso, com três repetições. O tamanho de parcela foi de $30 \mathrm{~m}^{2}(3 \mathrm{~m} \times 10 \mathrm{~m})$. Foram efetuadas análises de variância da conversão energética e do balanço energético dentro de cada ano (inverno + verão) e na média conjunta dos anos, nos períodos de 1987 a 1989 e de 1990 a 1995 . A análise de variância conjunta foi aplicada as duas seqüências de culturas em diferentes anos, em face das alterações efetuadas a partir de 1990. Nas análises de variância, consideraram-se como tratamentos as parcelas individuais (culturas) componentes dos sistemas em estudo. Nas análises conjuntas, considerou-se o efeito tratamento como fixo e o efeito do ano, como aleatório. A avaliação dos sistemas de produção, em todas as análises, foi realizada por meio do teste $\mathrm{F}$, usando-se contrastes que incluem os diferentes tratamentos dos sistemas de rotação envolvidos em cada comparação. Essa metodologia de contrastes (STEEL \& TORRIE, 1980) compara os sistemas dois a dois, em uma unidade de base homogênea. 


\section{RESULTADOS E DISCUSSÃO}

As médias de conversão energética e as de balanço energético, anuais e no conjunto dos anos, nos períodos de 1987 a 1989 e de 1990 a 1995 , e as comparações estatísticas, através de contrastes, dos sistemas de rotação de culturas podem ser observadas nas tabelas 2 a 5. Inicialmente, serão apresentados os resultados sobre conversão energética e, posteriormente, os de balanço energético.

Levando-se em conta a conversão energética anual, observa-se que só não houve diferenças significativas entre os sistemas em 1987 (Tabela 2). Isso pode ser devido aos índices de conversão energética que foram relativamente próximos tanto nas culturas de inverno (aveia preta, ervilhaca, linho e trigo) como nas de verão (milho e soja). No período de 1987 a 1989, o sistema I não diferiu do sistema II para conversão energética, em nenhum dos anos (Tabela 2). Nesse período de estudo, esses sistemas mostraram índices de conversão energética similares. O sistema III apresentou maior índice de conversão energética que os sistemas I, II e V, em dois dos três anos estudados (1988 e 1989). Isso foi devido à cultura de milho que, nesse período, apresentou maiores índices de conversão energética (nos sistemas III, IV e VI). Esses resultados assemelham-se com os dados relatados por SANTOS \& REIS (1995).

No período de 1990 a 1995 , os sistemas II, III, IV, V, VI e VII foram superiores, na maioria dos anos, para o índice de conversão energética, em relação ao sistema I (Tabela 3). Isso pode ser devido ao fato de que, ao longo desses anos, a sucessão trigo/soja (sistema I) produziu menores índices de conversão energética do que os demais sistemas em rotação de culturas (sistemas II, III, IV, V, VI) (Tabela 1). Esses resultados são similares aos obtidos por SANTOS \& REIS (1994). O sistema II foi superior aos sistemas III, IV, V e VI em três anos (1991, 1992 e 1994), inferior em dois anos (1990 e 1993) e não diferiu em um ano (1995). Como havia trigo/soja e ervilhaca/milho em todos os sistemas estudados, essa diferença pode ser atribuída à aveia branca, no inverno, e ao girassol e demais tratamentos com soja, no verão (Tabela 1), que apresentaram menores índices de conversão energética. $\mathrm{O}$ sistema II foi superior aos sistema VII em três anos (1992, 1994 e 1995) e inferior em três anos (1990, 1991 e 1993).

Nas avaliações anuais dos dois períodos de estudo (de 1987 a 1989 e de 1990 a 1995), os sistemas com rotação de culturas foram mais eficientes na conversão de energia, na maioria dos anos, que a monocultura (Tabelas 2 e 3). Pelos resultados, supõe-se que os baixos desempenhos energéticos das culturas de cobertura de solo, no inverno, foram compensados, em parte, principalmente pelo maior desempenho da cultura de milho, no verão. Resultados semelhantes foram obtidos por SANTOS et al. (1996b), comparando índices de produtividade cultural (resultado da divisão do rendimento de grãos de cada espécie 
Tabela 3 - Conversão energética e contraste pelo teste $\mathrm{F}$ de sete sistemas de rotação de culturas no ano (inverno + verão) e na média dos anos, de 1990 a 1995, Passo Fundo, RS, 1999.

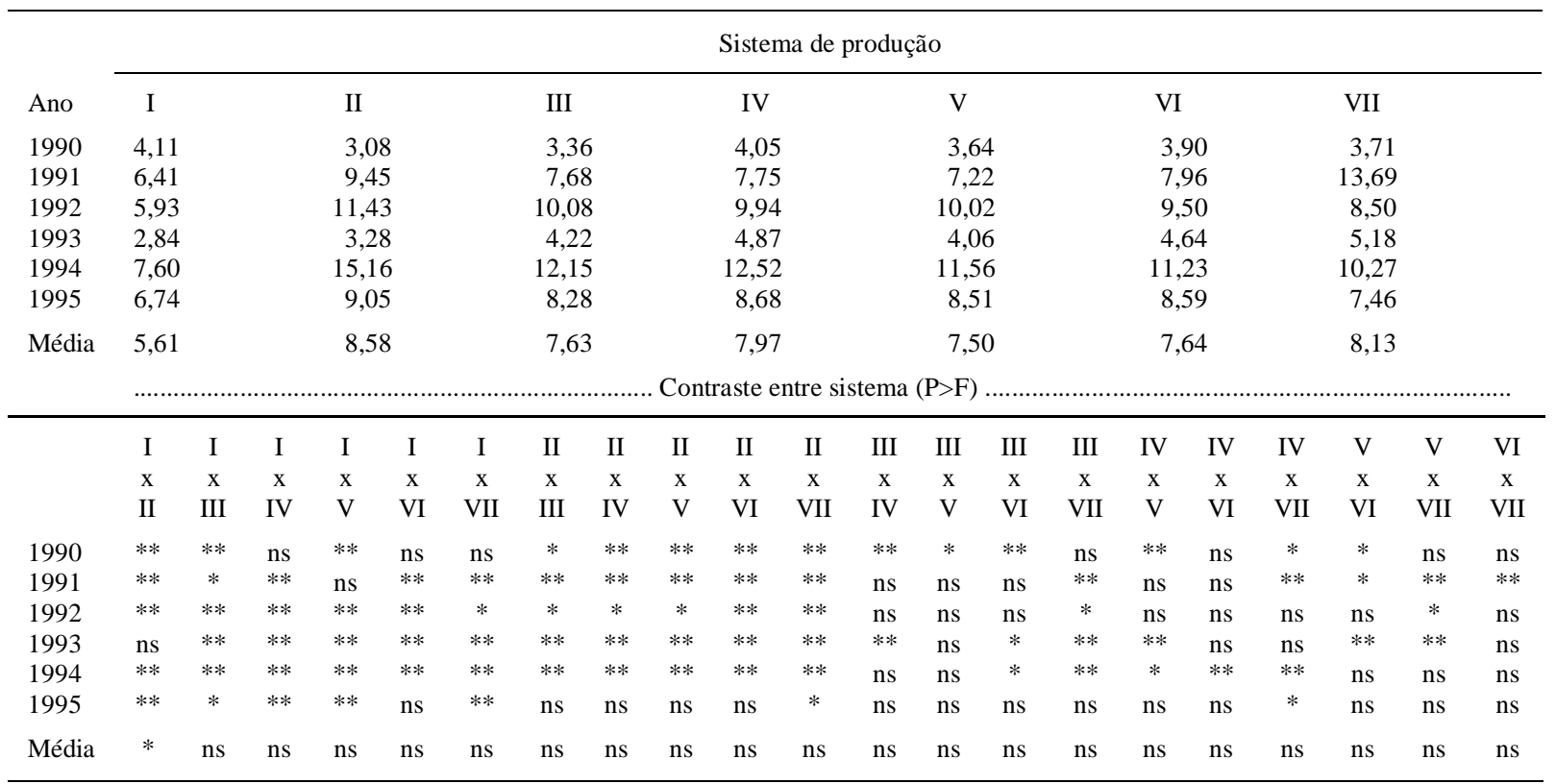

Sistema I: trigo/soja.

Sistema II: trigo/soja e ervilhaca/milho ou sorgo.

Sistema III: trigo/soja, aveia branca e ervilhaca/milho ou sorgo.

Sistema IV: trigo/soja, girassol ou aveia preta/soja, aveia branca/soja e ervilhaca/milho ou sorgo.

Sistema V: trigo/soja, trigo/soja, aveia branca e ervilhaca/milho ou sorgo.

Sistema VI: trigo/soja, trigo/soja, girassol ou aveia preta/soja, aveia branca/soja e ervilhaca/milho ou sorgo.

Sistema VII: pousio/soja.

ns: não significativo; * : significância a $5 \% ; * *$ : significância a $1 \%$.

pela energia consumida) para sistemas de rotação de culturas com trigo, durante dez anos, sob sistema plantio direto. O melhor sistema para essa gramínea foi de um inverno de rotação, em relação à sucessão trigo/soja.

As análises de variância conjunta dos dados para conversão energética, nos dois períodos (1987 a 1989 e 1990 a 1995), apresentaram significância quanto aos efeitos anos e interação anos $\mathrm{x}$ tratamentos (espécies), indicando que essas variáveis foram afetadas pelas variações climáticas ocorridas entre os anos. Todavia, essa significância não se expressou para a média dos anos, no primeiro período de estudo. Houve ainda significância para o efeito tratamentos somente no segundo período.

De 1987 a 1989, os sistemas I a VI não diferiram entre si para conversão energética média (Tabela 2). Deve ser levado em consideração que, embora não tenham ocorrido diferenças significativas entre os índices médios de conversão energética avaliados, os sistemas III, IV, V e VI, por incorporarem a prática de rotação de culturas em seus sistemas (Tabela 1), devem ser preferidos em substituição aos sistemas I e II (sucessão trigo/soja, nesse período). Conforme pode ser observado, nesse período havia dois sistemas em monocultura. À medida que as doenças de trigo se agravaram no sistema II, a partir de 1990, este foi substituído pela rotação trigo/soja e ervilhaca/milho ou sorgo.

As médias comparadas duas a duas de 1990 a 1995 mostram que somente o sistema II foi superior ao sistema I para o índice de conversão energética (Tabela 3). Nesse período, o sistema II era formado por trigo/soja e ervilhaca/milho. Para as demais comparações entre sistemas de sucessão ou de rotação de culturas, não houve diferenças significativas, em relação à conversão energética. O sistema VII foi estabelecido, em 1990, como pousio de inverno e soja no verão. O sistema (II) com um inverno de rotação constituiu em alternativa para substituir o sistema I (sucessão trigo/soja).

Pelo observado, nos dois períodos, todos os sistemas estudados foram positivos, por apresentarem índices de conversão energética superiores à unidade $(1,0)$ (QUESADA \& BEBER, 1990). Do ponto de vista energético, todos os sistemas estudados podem ser considerados sustentáveis. 
Considerando o balanço energético anual, verifica-se que houve diferenças significativas entre os sistemas estudados em todos os anos (Tabelas $4 \mathrm{e}$ 5). No período de 1987 a 1989, o sistema I não diferiu do sistema II para balanço energético (Tabela 4). Nesse período de estudo, esses sistemas apresentaram índices de balanço energético semelhantes. Os sistemas III e IV foram superiores ao sistema I nos dois anos (1988 e 1989) e inferiores em 1987. A explicação, em parte, para essa diferença pode ser atribuída ao fato que, nos sistemas III e IV, havia rotação de culturas, em relação ao sistema $\mathrm{I}$, em sucessão trigo/soja. Como o sistema II, nesse período, era idêntico ao sistema I, não apresentou o mesmo comportamento, em relação aos demais sistemas em rotação de culturas. Os sistemas III, IV, V e VI, que foram programados em rotação de culturas, não apresentaram grandes diferenças entre si para os índices de balanço energético.

No período de 1990 a 1995 , os sistemas II, III, IV, V e VI foram superiores em três anos, inferiores em um ano (1990) e não diferiram em dois anos, para os índices de balanço energético, em comparação ao sistema I (Tabela 5). Essa diferença

Tabela 4 - Balanço energético e contraste pelo teste $\mathrm{F}$ de seis sistemas de rotação de culturas no ano (inverno + verão) e na média dos anos de 1987 a 1989, Passo Fundo, RS, 1999.

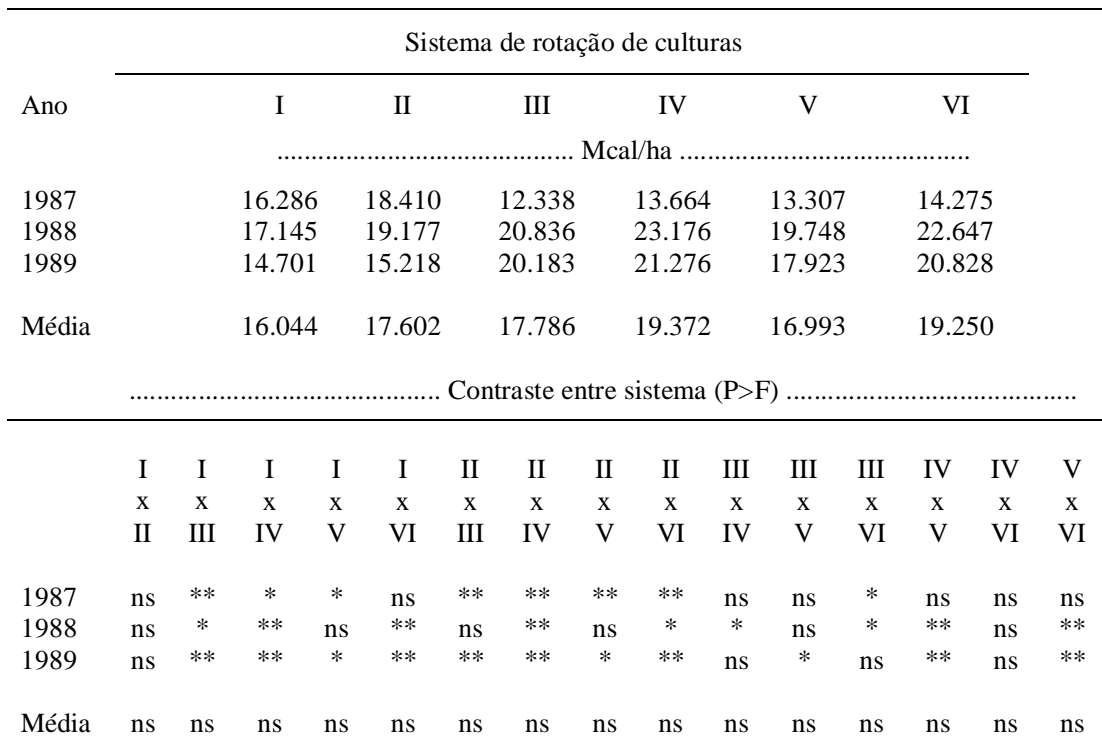

Sistema I: trigo/soja.

Sistema II: trigo/soja e ervilhaca/milho ou sorgo.

Sistema III: trigo/soja, aveia preta e ervilhaca/milho ou sorgo.

Sistema IV: trigo/soja, girassol ou aveia preta/soja, aveia branca/soja e ervilhaca/milho ou sorgo.

Sistema V: trigo/soja, trigo/soja, aveia branca e ervilhaca/milho ou sorgo.

Sistema VI: trigo/soja, trigo/soja, girassol ou aveia preta/soja, aveia branca/soja, e ervilhaca/milho.

ns: não significativo.

*: significância a $5 \%$.

**: significância a $1 \%$. pode ser atribuída à rotação de culturas (sistemas II, III, IV, V e VI), em relação à sucessão trigo/soja (sistema I). O sistema I, quando comparado ao sistema VII, não diferiu em dois anos (1991 e 1993) e foi superior em quatro anos (1990, 1992, 1994 e 1995). No sistema VII, havia somente uma cultura no verão (soja), em comparação com o sistema I (trigo/soja). Comparado aos sistemas III, IV e VI, o sistema II foi superior em três anos (1991, 1992 e 1994), não diferiu em um ou dois anos e foi inferior em um ou dois anos. O sistema II não diferiu em dois anos (1992 e 1995) do sistema V, superou-o em dois anos (1991 e 1994) e apresentou-se inferior a ele em dois anos (1990 e 1993). Como havia trigo/soja e ervilhaca/milho em todos os sistemas estudados, essa diferença pode ser atribuída à aveia branca, no inverno, e ao girassol e demais tratamentos com soja, no verão, que apresentaram menores índices de balanço energético. Com relação, ao sistema VII, o sistema II não diferiu em 1993 e foi superior nos demais anos. Trata-se da vantagem de rotação de culturas no inverno (sistema II) contra o pousio de inverno (sistema VII). Não houve grandes diferenças entre os sistemas com rotação de culturas (sistemas II, III, IV, V e VI) para os índices de balanço energético.

Para o balanço energético anual, na maioria dos anos, repetiu-se o desempenho da conversão energética dos sistemas com rotação de culturas, em relação à monocultura (Tabelas 4 e 5).

$\mathrm{Na}$ análise conjunta do balanço energético, nos dois períodos (1987 a 1989 e 1990 a 1995), encontraram-se resultados semelhantes aos da conversão energética. Houve significância para o efeito tratamento somente no segundo período.

De 1987 a 1989, não houve diferença significativa entre os sistemas estudados para balanço energético (Tabela 4). Pelos resultados anuais, os sistemas com rotação de culturas apresentaram-se como alternativas para substituir a monocultura trigo/soja, pois, no segundo ano, e mais acentuadamente no terceiro ano, estes superaram a monocultura. 
Tabela 5 - Balanço energético e contraste pelo teste F de sete sistemas de rotação de culturas no ano (inverno + verão) e na média dos anos, de 1990 a 1995, Passo Fundo, RS, 1999.

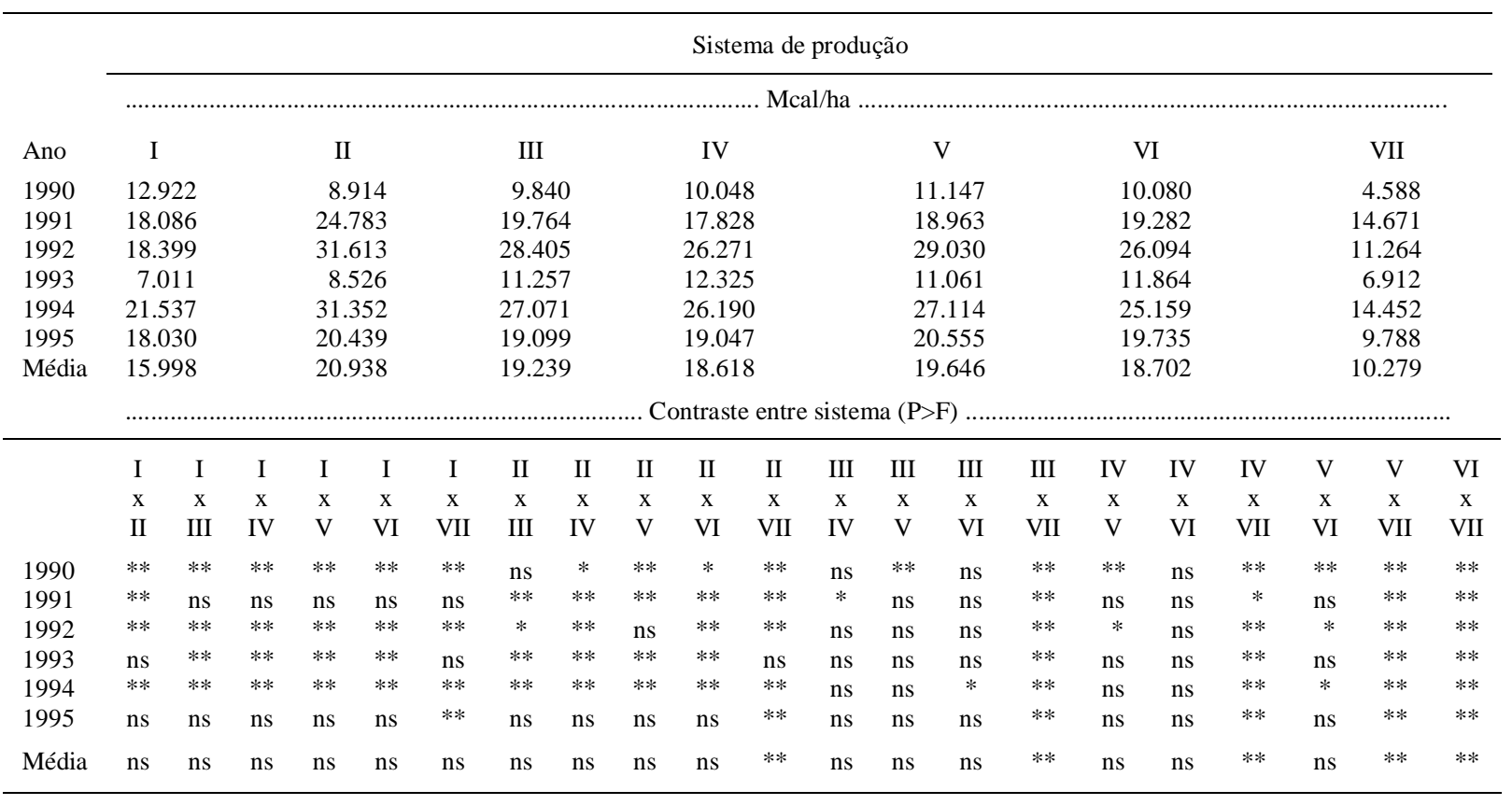

Sistema I: trigo/soja.

Sistema II: trigo/soja e ervilhaca/milho ou sorgo.

Sistema III: trigo/soja, aveia branca e ervilhaca/milho ou sorgo.

Sistema IV: trigo/soja, girassol ou aveia preta/soja, aveia branca/soja e ervilhaca/milho ou sorgo.

Sistema V: trigo/soja, trigo/soja, aveia branca e ervilhaca/milho ou sorgo.

Sistema VI: trigo/soja, trigo/soja, girassol ou aveia preta/soja, aveia branca/soja e ervilhaca/milho ou sorgo.

Sistema VII: pousio/soja.

ns: não significativo; * : significância a 5\%; ** : significância a $1 \%$.

De 1990 a 1995, os sistemas II, III, IV, V e VI foram superiores ao sistema VII para balanço energético (Tabela 5). Por outro lado, o sistema I não diferiu significativamente dos sistemas II, III, IV, V, VI e VII. O sistema VII, adicionado em 1990, com pousio de inverno e soja, no verão, foi menos eficiente energeticamente do que os demais sistemas estudados. Isso era de se esperar porque havia somente uma cultura no verão.

Deve ser levado em conta que as tecnologias agrícolas usadas nos sistemas estudados foram eficientes em termos de conversão energética e de balanço energético. Dessa forma, a rotação de culturas foi mais eficiente, sem aumentar o consumo de energia não renovável (exemplo: combustíveis, fertilizantes, fungicidas, herbicidas e inseticidas).

\section{CONCLUSÕES}

Todos os sistemas de sucessão ou de rotação de culturas apresentaram balanço energético positivo e podem ser considerados viáveis.

Os sistemas com rotação de culturas, na maioria dos anos, foram energeticamente mais eficientes do que a monocultura trigo/soja ou pousio/soja.

\section{REFERÊNCIAS BIBLIOGRÁFICAS}

BERARDI, G.M. Organic and conventional wheat production: examination of energy and economics. Agro-Ecosystems, Amsterdam, v.4, n.3, p.367-376, 1978.

BOHRA, C.P., VARSHNEY, A.C, NARANG, S. Energy and cost audit of bullock and power tiller farming system in soybean and wheat crop production. Journal of Scientific \& Industrial Research, Bhopal, v.49, n.12, p.583-588, 1990.

COMISSÃO DE FERTILIDADE DO SOLO - RS/SC. Recomendações de adubação e de calagem para os estados do Rio Grande do Sul e Santa Catarina. 3.ed. Passo Fundo : SBCS-Núcleo Regional Sul, 1995. 223p.

DERPSCH, R., CALEGARI, A. Plantas para adubação verde de inverno. Londrina: IAPAR, 1992. 80p. (IAPAR. Circular, 73).

EMBRAPA. Centro Nacional de Pesquisa de Suínos e Aves (Concórdia, SC). Tabela de composição química e valores energéticos de alimentos para suínos e aves. 3.ed. Concórdia : EMBRAPA, 1991. 97p. (EMBRAPA-CNPSA. Documentos, 19). 
FREITAS, E.A.G. de, DUFLOTH, J.H., GREINER, L.C. Tabela de composição química-bromatológica e energética dos alimentos para animais ruminantes em Santa Catarina. Florianópolis: EPAGRI, 1994. 33p. (EPAGRI. Documentos, $155)$

HEICHEL, G.H. Assessing the fossil energy costs of propagating agricultural crops. In: PIMENTEL, D., (ed.) Handbook of energy utilization in agriculture. Boca Raton: CRC, 1980. p.27-33

MARCHIORO, N. de P.X. Balanço ecoenergético: uma metodologia de análise de sistemas agrícolas. In: TREINAMENTO EM ANÁLISE ECOENERGÉTICA DE SISTEMAS AGRÍCOLAS, 1, 1985, Curitiba. Anais... Curitiba : IAPAR, 1985. 57p. p.24-40.

MELLO, R. de. Análise energética de agroecossistemas: o caso de Santa Catarina. Florianópolis, 1986. 139p. Dissertação (Mestrado em Engenharia) - Curso de Engenharia de Produção-UFSC, 1986

MUZILLI, O. Fertilidade do solo em plantio direto. In FANCELLI, A.L., TORRADO, P.V., MACHADO, J. Atualização em plantio direto. Campinas : Fundação Cargill, 1985. Cap.7, p.147-160.

PIMENTEL, D. Energy inputs for the production, formulation, packaging, and transport of various pesticides. In: PIMENTEL, D., ed. Handbook of energy utilization in agriculture. Boca Raton : CRC, 1980a. p.45-48.

PIMENTEL, D. Handbook of energy utilization in agriculture. Boca Raton : CRC, 1980b. 475p.

QUESADA, G.M., BEBER, J.A.C. Energia e mão-de-obra Ciência Hoje, Rio de Janeiro, v.11, n.62, p.21-26, 1990.

QUESADA, G.M., BEBER, J.A.C., SOUZA, S.P. de. Balanços energéticos agropecuários: uma proposta metodológica para o Rio Grande do Sul. Ciência e Cultura, São Paulo, v.39, n.1, p.20-28, 1987

REIS, E.M., SANTOS, H.P. dos. Interações entre doenças de cereais de inverno e sistema plantio direto. In: EMBRAPA Centro Nacional de Pesquisa de Trigo (Passo Fundo, RS). Plantio direto no Brasil. Passo Fundo : EMBRAPACNPT/FUNDACEP FECOTRIGO/Fundação ABC/Aldeia Norte, 1993. p.105-110.

ROMAN, E.S., VELLOSO, J.A.R. de O. Controle cultural, coberturas mortas e alelopatia em sistemas conservacionistas. In: EMBRAPA. Centro Nacional de Pesquisa de Trigo (Passo Fundo, RS). Plantio direto no Brasil. Passo Fundo : EMBRAPA-CNPT/FUNDACEP FECOTRIGO/Fundação ABC/Aldeia Norte, 1993. p.77-84

SANTOS, H.P. dos, FONTANELI, R.S., IGNACZAK, J.C., et al. Conversão e balanço energético de sistemas de produção de grãos, incluindo soja e pastagens anuais de inverno, sob sistema plantio direto. In: EMBRAPA. Centro Nacional de Pesquisa de Trigo (Passo Fundo, RS). Soja: resultados de pesquisa do Centro Nacional de Pesquisa de Trigo, 1995/96. Passo Fundo : EMBRAPA-CNPT, 1996a. p.174-186, 246p. (EMBRAPA-CNPT. Documentos, 28).

SANTOS, H.P. dos, IGNACZAK, J.C., LHAMBY, J.C.B. Produtividade cultural de sistemas de rotação de culturas para trigo, durante dez anos, em Passo Fundo, RS. Pesquisa Agropecuária Brasileira, Brasília, v.30, n.12, p.1397-1402, dez, 1995.

SANTOS, H.P. dos, IGNACZAK, J.C., WOBETO, C. Produtividade cultural de sistemas de rotação de culturas com trigo, sob plantio direto. Pesquisa Agropecuária Brasileira, Brasília, v.31, n.4, p.277-282, abr, 1996b.

SANTOS, H.P. dos, REIS, E.M. Rotação de culturas em Guarapuava, PR. Brasil. XVI. Eficiência energética dos sistemas de rotação de culturas com trigo, em plantio direto. Pesquisa Agropecuária Brasileira, Brasília, v.30, n.2, p.215-222, fev, 1995.

SANTOS, H.P. dos, REIS, E.M. Rotação de culturas em Guarapuava, PR. Brasil. XVII. Eficiência energética dos sistemas de rotação de culturas para cevada, em plantio direto. Pesquisa Agropecuária Brasileira, Brasília, v.29, n.7, p.1075-1081, jul, 1994.

SANTOS, H.P. dos, REIS, E.M., DERPSCH, R. Rotação de culturas. In: EMBRAPA. Centro Nacional de Pesquisa de Trigo (Passo Fundo, RS). Plantio direto no Brasil. Passo Fundo : EMBRAPA-CNPT/FUNDACEP FECOTRIGO/ Fundação ABC/Aldeia Norte, 1993. p.85-103.

STEEL, R.G.D., TORRIE, J.H. Principles and procedures of statistics: a biometrical approach. 2.ed. New York : McGraw-Hill, 1980. 633p.

WHITE, D.J. Energy in agricultural systems. The Agricultural Engineer, Bedford, v.30, n.3, p.52-58, 1975.

WILSON, P.N., BRIGSTOCKE, T.D.A. Energy usage in Bristish agriculture - a review of future prospects. Agricultural Systems, Essex, v.5, n.1, p.51-70, 1980 .

ZENTNER, R.P., CAMPBELL, D.W., CAMPBELL, C.A., et al. Energy consideration of crop rotation in southwestern Saskatchewan. Canadian Agricultural Engineering, Ottawa, v.26, n.1, p.25-29, 1984.

ZENTNER, R.P., STUMBORG, M.A., CAMPBELL, C.A Effect of crop rotations and fertilization on energy balance in typical production systems on the Canadian prairies. Agriculture, Ecosystems and Environment, Amsterdam, v.25, n.2/3, p.217-232, 1989.

Ciência Rural, v. 31, n. 2, 2001. 